\title{
O processo criativo de pacientes internados para tratamento quimioterápico: uma contribuição a partir do pensamento de $\mathrm{D}$. W. Winnicott*
}

\author{
The creative process for chemotherapy in-patients: a contribution from \\ the thought of D. W. Winnicott
}

\author{
Marcia Regina Motta ${ }^{1}$, Maria José Gugelmin de Camargo ${ }^{2}$, Nadja Nara Barbosa \\ Pinheiro $^{3}$
}

http://dx.doi.org/10.11606/issn.2238-6149.v24i2p141-148

Motta MR, Camargo MJG, Pinheiro NNB. O processo criativo de pacientes internados para tratamento quimioterápico: uma contribuição a partir do pensamento de D. W. Winnicott. Rev. Ter. Ocup. Univ. São Paulo, 2013 maio/ago, 24(2);141-8.

RESUMO: A experiência da Terapia Ocupacional no uso de atividades como instrumento terapêutico possibilita a promoção de um espaço de criatividade. Neste sentido o estudo buscou identificar o modo pelo qual o paciente vivencia o processo criativo, ao desenvolver atividades durante o período de internamento e tratamento quimioterápico. Constituindo-se em um estudo de abordagem clinico qualitativa, que utilizou o referencial teórico da teoria do amadurecimento de D. W. Winnicott. Para sua realização, foram realizados 5 encontros individuais com 9 pacientes internados para tratamento quimioterápico. O primeiro encontro foi destinado a entrevista inicial e nos demais encontros a proposta consistiu em realizar uma atividade. Ao final de cada encontro o paciente respondia a uma entrevista semi estruturada, que foi audiogravada e o material coletado transcrito. As informações obtidas foram submetidas à análise de conteúdo. A partir desse processo emergiram seis categorias temáticas: a vivência do tempo, o brincar no processo criativo, a subjetividade na ação, a criatividade como metáfora, o emergir da criatividade e crença religiosa. Verificou-se que o processo de realização de atividade apresentou-se como um ato criativo que expressava o modo particular pelo qual cada paciente atribuía sentido e significado as suas experiências no mundo.

DESCRITORES: Terapia ocupacional; Hospitalização; Atividades humanas; Criatividade.
Motta MR, Camargo MJG, Pinheiro NNB. The creative process for chemotherapy in-patients: a contribution from the thought of D. W. Winnicott. Rev. Ter. Ocup. Univ. São Paulo, 2013 maio/ ago, 24(2);141-8.

ABSTRACT: The experience of Occupational Therapy using activities as therapeutic tools promotes a space for creativity. Within this context, we sought to identify the way in which the patient experiences the creative process, while developing activities during his time of hospitalization and chemotherapy. It is a clinical study of qualitative approach and its theoretical framework was guided by the theory of maturation by D. W. Winnicott. To achieve our objective, 5 private meetings were held with 9 patients admitted for chemotherapy; the first meeting intended to an initial interview and the following meetings intended to performing an activity. At the end of each meeting the patient responded to a semi-structured interview, which was recorded and later on transcribed. The information collected was later subject to content analysis. From this process six thematic categories emerged: the experience of time, the play in the creative process, subjectivity in action, creativity as a metaphor, the emergence of creativity and religious belief. It was found that the process of performing an activity showed itself as a creative act that expressed the particular way through which each patient gave meaning and significance to their experiences in the world.

KEYWORDS: Occupational therapy; Hospitalization; Human activities. Creativity.

*Trabalho de Conclusão de Curso (TCC) do Programa de Residência Multiprofissional Integrada em Atenção Hospitalar do Hospital de Clínicas da Universidade Federal do Paraná (HC/UFPR), com aprovação no Comitê de Ética do HC/UFPR, de acordo com o parecer nº 21788.

1.Residente de Terapia Ocupacional do Programa de Residência Multiprofissional Integrada em Atenção Hospitalar do Hospital de Clínicas da Universidade Federal do Paraná (PRMIAH-HC/UFPR).

2.Docente do Curso de Terapia Ocupacional do Departamento de Terapia Ocupacional da Universidade Federal do Paraná.

3.Docente do Curso de Psicologia do Departamento de Psicologia da Universidade Federal do Paraná.

Endereço para correspondência: Rua Eurípedes Moraes e Silva, 888. Conj. Áquila. Pinhais, PR. CEP: 83.326-130. E-mail: mjmmml@ gmail.com 


\section{INTRODUÇÃO}

$\mathrm{O}$ estado de adoecimento orgânico pode se apresentar como um fator que sufoca o processo criativo do indivíduo e desvincula o viver criativo do viver propriamente dito ${ }^{1}$. Neste sentido, é que este trabalho visa abordar a atividade artística como instrumento terapêutico utilizado pela terapia ocupacional, que promove espaço de criação que possibilita que a pessoa em situação de internamento assuma uma atitude criativa perante a realidade: favorece o viver criativo e permite o agir sobre o mundo. Esta reflexão toma os conceitos da teoria de Winnicott como norteadora. Inicialmente o texto apresentará a emergência de um sujeito considerado a partir da experiência do viver criativo. Em seguida, será descrito a pesquisa realizada com pessoas em tratamento quimioterápico e a função que a atividade artística assume no campo da terapia ocupacional.

\section{A constituição do sujeito e a criação}

Ao nascer o bebê acha-se numa condição de total dependência e desamparo, tanto em termos biológico quanto psíquico, e o ambiente (que pode ser pensado não apenas como espaço físico, mas também como cuidado materno) promove a satisfação de suas necessidades. A mãe adapta-se ativamente às demandas de seu bebê, proporcionando cuidados no momento certo e na intensidade adequada para satisfazê- $\mathrm{lo}^{2}$.

Para Winnicott ${ }^{2}$, essa adaptação permite ao bebê ter a ilusória experiência de onipotência de que tudo o que acontece vem dele e é por ele criado, isto implica no fato de que, inicialmente, o bebê pode ser considerado um ser indiferenciado com o ambiente. A mãe não é algo externo, nem interno ao bebê, pois, os sentidos da exterioridade e do mundo interno ainda não se constituíram ${ }^{3,4}$.

No processo de integrar-se, o bebê começa a poder suportar uma gradual desadaptação do ambiente, e assim, a adaptação da mãe diminui gradativamente à medida que cresce a capacidade do bebê em absorver o fracasso do ambiente e em tolerar os resultados da frustração. A mãe, ao mostrar-se diferente, ao não se ajustar totalmente às demandas e não se mostrar como continuidade, favorece ao bebê uma experiência de contorno, uma diferenciação entre o eu e o não-eu, entre as realidades interior e exterior $^{2,3,5}$

Neste processo rumo à integração, à personalização e à realidade, a experiência ilusória de onipotência do bebê proporcionada pela adaptação de uma mãe "suficientemente boa" é primordial, e garante outro tipo de ilusão típica das crianças pequenas, que corresponde aos "fenômenos e objetos transicionais". De acordo com Winnicott ${ }^{2}$, estes são conceitos que se referem a uma área neutra de experiência, incontestada quanto a pertencer à realidade interna ou externa, área intermediária na qual se dá a maior parte da relação do bebê com o mundo. Esse território permanece para toda a vida e é o espaço onde a vida mesma acontece.

No que se refere, a maneira de viver no mundo, Winnicott ${ }^{1}$ destaca a importância do viver criativamente. Concebe a criatividade como relacionada ao estar vivo e como um colorido de toda a atitude do individuo perante a realidade externa, de modo que, ao apresentar-se operante no mundo, tudo o que acontece é criativo e consequência do estabelecimento da capacidade pessoal para o viver criativo.

Para pessoas com diagnóstico de câncer, essa experiência bem como a vivencia do tratamento, acrescida da necessidade de internamento, acarreta alto nível de desequilíbrio e estresse, decorrente do impacto físico, social e emocional que o enfrentamento desta condição impõe. Esse conjunto de aspectos pode repercutir no modo de agir sobre o mundo e conduzir a um prejuízo da capacidade criativa em relação à vida ${ }^{6}$.

Frente a fatores ambientais que podem sufocar o processo criativo, é importante liberar a criatividade, para que o sujeito possa sair de um estado onde não é possível criar, para outro em que seja possível a manifestação da capacidade pessoal para o viver criativo. Para esses sujeitos é importante oferecer dispositivos clínicos no contexto hospitalar que favoreçam a construção de um cotidiano saudável, compreendendo que saudável, constitui-se em viver criativamente e tem íntima relação com o estar vivo ${ }^{1}$.

Nessa direção a criação artística, considerada como atividade humana e concebida como a junção da dinâmica de realização de atividade- com sua técnica, seus materiais e equipamentos - e a dinâmica psíquica do sujeito em ação, se apresenta como recurso que favorece campos de experimentação que possibilitam ao individuo criar, mapear seu mundo e nos quais o sujeito e seu estilo de ser se constituem esteticamente ${ }^{7}$.

Este estudo procurou identificar o modo pelo qual o paciente vivencia o processo criativo, ao desenvolver algumas atividades durante o período de internamento e tratamento quimioterápico, e analisar a função da criação artística na terapia ocupacional.

\section{MÉTODO}

O estudo empregou abordagem clínico qualitativa, 
que se configurou no estudo dentro do setting natural, preocupando-se com o processo, buscando melhor compreender a experiência humana e como as pessoas constroem significados ${ }^{8}$.

Foram participantes 9 sujeitos que apresentam diagnóstico de câncer hematológico e que se encontravam internados na Unidade de Quimioterapia de Alto Risco, do Hospital de Clínicas da Universidade Federal do Paraná (HC-UFPR), no período de junho a novembro de 2012.

Do total de participantes, $67 \%$ (6) eram do sexo feminino e $33 \%$ (3) do sexo masculino. Em relação ao estado civil, observou-se superioridade numérica de solteiros, correspondendo a seis sujeitos, seguido de dois casados e um viúvo. O nível de escolaridade apontou 56\% (5) dos participantes possuindo ensino fundamental, $22 \%$ (2) tinham o ensino médio e $22 \%$ (2) o nível superior.

Quanto ao diagnóstico, constatou-se uma maior concentração de sujeitos com Leucemia Mielóide Aguda, equivalendo a $67 \%$ (6) dos participantes, aparecendo também, embora com uma frequência mais discreta, $22 \%$ (2) dos sujeitos com Leucemia Linfóide Aguda, e 11\% (1) dos participantes com Linfoma de Hodgkin. A faixa etária variou de 18 a 48anos.

O estudo foi realizado em observância à norma 196/96 do Conselho Nacional de Saúde e suas complementares, com aprovação junto ao Comitê de Ética e Pesquisa em Seres Humanos (CEP) do HC-UFPR (processo $\mathrm{n}^{\circ} 21788 / 2012$ ). Foram elucidados previamente os objetivos da pesquisa e assegurou-se o caráter de sigilo e anonimato dos participantes. Sendo que a efetivação da participação somente ocorreu após o sujeito ter concordado e assinado o Termo de Consentimento Informado Livre e Esclarecido (TCLE), aprovado pelo CEP/HC-UFPR.

Para a concretização da pesquisa propôs-se, a cada participante, cinco encontros, em dias intercalados, com duração máxima de 60 minutos. O primeiro encontro era destinado a entrevista inicial. Em cada um dos quatro encontros restantes a proposta consistia em realizar uma atividade, de modo que era oferecido ao participante um conjunto de materiais a serem utilizados durante os encontros, ficando livre para usá-los, no processo de realização da atividade, do modo como lhe aprouvesse.

Foram disponibilizados: papel sulfite, cola, tesoura sem ponta, revista, lápis preto, lápis de cor, giz de cera, borracha, tela para pintura, pincel e tinta acrílica não tóxica. Cada participante recebia um conjunto de material que não eram repostos após utilizados. Tal procedimento visava estimular que o participante encontrasse maneiras de agir diante dos recursos disponíveis e quando da ausência dos mesmos.
Após concluir a atividade realizada, o participante era convidado a responder uma entrevista semiestruturada, cujo roteiro temático tomou como base a literatura da área, os interesses de pesquisa e a experiência dos pesquisadores. Este roteiro foi composto por questões norteadoras, que exploravam, principalmente, a percepção da vivência do processo de elaboração da atividade.

As entrevistas foram audiogravadas e o material coletado foi transcrito literalmente e na íntegra, respeitando o linguajar peculiar dos participantes, com a intenção de resguardar a autenticidade e vivacidade das falas, e manter a espontaneidade na qual se deram os encontros, em detrimento da observância rigorosa da norma culta da língua portuguesa9 .

Os encontros transcorreram entre junho e novembro de 2012, compondo o total de 45 atendimentos, sendo que, nove corresponderam à entrevista inicial e 36 foram destinados à proposta de realização de atividade. Destes, 24 foram encontros nos quais os participantes realizaram a atividade conforme proposto, e em 12 não foram realizadas atividades.

A piora do quadro clínico, alterações emocionais e sintomas físicos consequentes da doença, do tratamento e do internamento, além de questões de ordem pessoal e familiar se apresentaram como aspectos que levaram os pacientes a recusarem a proposta de realizar a atividade ou ainda os impossibilitaram de engajarem-se nela.

Após a coleta dos dados e transcrições das entrevistas, as informações foram submetidas à Análise de Conteúdo, definida por $\operatorname{Bardin}^{10}$ (p.18), como "um conjunto de técnicas de análise das comunicações", onde o que se dá é o tratamento da informação contida na mensagem. A organização da análise ocorreu em torno de três polos: pré-análise, exploração do material, tratamento dos resultados obtidos e interpretação de acordo com o referencial teórico. Durante a pré-análise foi realizada leitura flutuante do material, e estabelecimento de núcleos estruturadores recorrentes nos discursos. A fase de exploração do material procurou atingir o núcleo de compreensão do texto, através da classificação em categorias temáticas. Por fim, na última etapa, foi realizada a interpretação dos resultados, mediante articulação do corpo teórico com os dados obtidos.

Todos os autores participaram do processo de elaboração da proposta de pesquisa, da análise dos dados, da obtenção dos resultados e da discussão, enriquecendo o estudo com as contribuições e articulações teóricas.

A partir do processo da pesquisa emergiram seis categorias temáticas, que serão apresentadas e discutidas na sequência. São elas: a vivência do tempo, o brincar no 
processo criativo, a subjetividade na ação, a criatividade como metáfora, o embotamento da criatividade e crença religiosa.

\section{RESULTADOS E DISCUSSÃO}

\section{A vivência do tempo}

A partir do convite para criar utilizando materiais disponibilizados, os participantes destacaram a questão do tempo como fator motivador para o engajamento na proposta. Verbalizaram a percepção de um tempo que passava mais rápido quando se encontravam envolvidos na realização da atividade.

"Eu aceitei realizar essa atividade pra distrair um pouco e sair um pouco da rotina do quarto, só de ficar deitado assistindo TV, então isso ajudou bastante a me distrair essa tarde, como passou o tempo também” (G).

Observou-se, que para a pessoa em situação de internamento a percepção da passagem do tempo parece correr lenta e morosa, marcada por um tempo da espera da melhora do quadro clínico e do consequente retorno para casa, tempo vivenciado como que sem possibilidade de ação.

\footnotetext{
"Dá um distraimento, porque a gente fica aqui... tem hora que a gente se sente meio nervoso, vontade de ir pra casa. É sempre bom que você tenha alguma coisa pra fazer, pra se distrair. Você se sente bem” (D).

"Ah... a gente se distrai e passa mais rápido o tempo. E não fica só deitada. Cansa muito a gente só deitada" (E).
}

A condição vivenciada pelos participantes, que se encontravam internados e regidos pelas regras da estrutura hospitalar, vistos como pacientes, no sentido daquele que espera resignado e submisso, e, portanto, passivo, aponta para o prejuízo do viver criativo. Segundo Winnicott ${ }^{1}$, pode existir um relacionamento de submissão à realidade externa, onde o mundo é reconhecido como algo a que se adaptar o que implicaria num sentido de inutilidade. De forma que, após experimentar o viver criativo, facilmente reconhece-se quando não se está vivendo criativamente.

Para quem vive a subordinação de um tempo de espera, o desenvolvimento de atividade mostra-se como dispositivo que estimula o impulso criativo, compreendido como necessário para a inclinação saudável para algo ou realização de alguma coisa, sendo que através do processo de elaboração da atividade o impulso criativo pôde tomar forma e ser compartilhado. Agindo sobre o mundo o individuo teria a ideia de que a vida vale a pena ser vivida e o tempo assume sentido e significado ${ }^{1,2,11}$.

A noção da passagem do tempo está atrelada a relação que o sujeito mantém com o meio e com o investimento que faz a um objeto num determinado período, portanto, a forma como vivencia uma experiência mostra-se determinante na percepção de como o tempo transcorre ${ }^{12}$.

Neste sentido, percebeu-se que, para os participantes, o momento do atendimento da Terapia Ocupacional demonstrava ser um tempo próprio que corria veloz. Naquele momento não se esperava, se agia. E o modo como cada paciente vivenciava a realização da atividade, apontava para um tempo subjetivo da experiência do fluir da vida, e o tempo ganhava uma dimensão favorável, acrescido de uma energia vital espontânea ${ }^{13}$.

\footnotetext{
"Me senti normal, como se não tivesse nada. Como se não tivesse o câncer. Como se eu estivesse na minha casa desenhando, que é algo que eu gosto e já fazia. Nem parecia que eu estava no hospita." (G).

"Distrai bastante. É bom, a gente não fica só pensando em remédio, no tratamento e tudo. Dai distrai, passa mais depressa o tempo" (E).
}

Diante das limitações que a internação impõe, a realização de atividade se apresentou como recurso que possibilita que o tempo possa assumir uma dimensão de autenticidade e criação, e passe a se constituir em uma experiência de construção de significados. O que está de acordo com Porto e Bittencourt ${ }^{12}$, que afirmam que o investimento no potencial criativo dos sujeitos internados atualiza as potencialidades, abrindo espaço para a criatividade e atribuindo ao tempo real dimensões de uma realidade pessoal e subjetiva.

\section{O brincar no processo criativo}

Para Winnicott ${ }^{11,14}$ o brincar é uma experiência criativa e resultado da relação com um ambiente "suficientemente bom". Nele não há regras ou intromissões. Localiza-se num espaço-tempo. Não está dentro, na realidade psíquica interna e tampouco, está fora do indivíduo, localiza-se na área intermediária: espaço potencial. Ao brincar, a criança traz para este espaço objetos e fenômenos advindos da realidade externa e usaos em prol da realidade interna. Assim, maneja o que é exterior atribuindo significado e sentido pessoal ${ }^{11}$.

Tal como a criança, os adultos também brincam. 
Podem fazê-lo por meio da comunicação verbal, nas escolhas das palavras, no senso de humor, e também nas experiências culturais, como é o caso da atividade artística. Semelhante à criança que preenche o brincar com conteúdos de sua subjetividade, o adulto deixa sua marca particular no gesto de brincar. Assim, no que se refere ao ato criativo envolvido na produção estética, o brincar estaria no jogo de estilos, na escolha de materiais, no jogo que se instaura no processo criativo ${ }^{11,14}$.

No contexto desta pesquisa, observou-se o brincar no processo criativo através da decisão de usar este ou aquele material denotando algo de pessoal e particular por parte de quem escolhia.

"Sempre tive vontade de pintar em tela. Quando eu trabalhava na loja, eles sempre compravam essa tela e as tintas, e eu pensava: um dia decerto vou pintar essa tela. Nunca tinha pintado em tela, é a primeira vez" (D).

O oferecimento de matérias para a realização da atividade, a possibilidade de escolher o que usar, associadas à proposta de criar livremente permitiram aos participantes a constituição de um espaço semelhante ao do livre brincar, no qual se observou a espontaneidade das ações, a oportunidade para a experiência amorfa e para os impulsos criativos, motores e sensórios, que constituem a matéria-prima do brincar ${ }^{11}$.

O brincar é essencial para a manifestação da criatividade, sendo a atividade artística derivada deste, de modo que ao criar o indivíduo manipula fenômenos externos a serviço da subjetividade e veste estes fenômenos escolhidos com significado e sentido. Estaria aqui a subjetividade marcada por um potencial positivo, construtivo, criativo e de superação, apontando para um viver saudável - ligação com o mundo e ação sobre o mundo - espaço do viver criativo ${ }^{1,14}$.

\section{A subjetividade na ação}

A configuração dos atendimentos se apresentou aos participantes como a possibilidade da ação em contraste a passividade imposta pela realidade. Ao agir no mundo por meio da criação, os participantes atribuíam um toque pessoal à experiência. $\mathrm{O}$ valor parecia estar no processo vivenciado mais do que no produto, e as maneiras de fazer se constituíam enquanto espaços de experimentação que permitiam ao sujeito $\mathrm{criar}^{7,15}$.

"Eu queria desenhar a minha casinha quando eu for embora pra Fortaleza. Eu queria desenhar, eu acho que fica melhor com esse material” (H).

"Estava chovendo e eu queria vê se vem o sol, dai eu fiz o sol, fiz uma paisagem” (B).

Desde o nascimento, o ser humano encontra-se envolvido com a questão da relação entre aquilo que é objetivamente percebido e aquilo que é subjetivamente experimentado, de modo que a realidade externa até certo ponto é um fenômeno subjetivo ${ }^{1,2,16}$.

O processo criativo oferece a constante relação entre os mundos externo e interno. A experiência estética habita a transicionalidade entre eu e outro. Nesta relação intersubjetiva ocorre a experiência criativa ligada às coisas do mundo, há a possibilidade de conhecer o mundo e o outro de forma pessoal e significativa ${ }^{1,7}$.

\section{A criatividade como metáfora}

$\mathrm{Na}$ experiência de produção estética a criatividade assume papel fundamental para a construção de significados frente à realidade da vivência de sofrimento, e para além dela, para experiências que compõem o universo do sujeito. Ao perceber-se autor, o indivíduo sai do aprisionamento e imprime os conteúdos de suas vivências na criação de imagens e formas, desta maneira, rompe com um estado de passividade que impede a significação e os conteúdos passam, então, a pertencer ao nível da cultura, podem ser compartilhados e o processo criativo, ganha potência transformadora, criadora de sentido $^{1,7}$.

Os atendimentos buscaram promover um contexto que tornasse a criação possível, um ambiente de respeito pela capacidade criativa e seriedade com relação ao fazer, o que contribuiu para que o processo de realização de atividade e o produto, desse processo, fossem tomados pelos participantes como possibilidade de narrar suas histórias.

"Coração quer dizer que o coração bate bem forte pela família, pelos amigos. Flor, flor é sempre bom uma flor, se não tiver flor então, nem se fala. E o coração quer dizer vida. Vida que cada dia estas internações que eu fiz até agora, cada dia minha vida tá mudando pra melhor, graças a Deus e, e forças pra luta contra a doença" (D).

"Eu tinha muita vontade de fazer um mural com toda a minha família, mas a gente acha que nunca sobra tempo, que na verdade a realidade é essa dai: a família em primeiro lugar abaixo de Deus. A realidade é a família" $(\mathrm{H})$. 
No percurso de amadurecimento, o indivíduo é empurrado na direção da realidade que lhe é externa e compartilhada, porém sem deixar de atribuir à realidade a experiência do mundo subjetivo ${ }^{1,4,11,14,17}$.

Assim, embora existisse, por parte dos participantes, a aceitação do adoecimento, articulada ao reconhecimento da realidade externa, notava-se que a experiência de criação abria possibilidade de apropriação simbólica dessa realidade ${ }^{7,18}$.

Deste modo, o processo de criação mostrouse promotor para que a realidade objetiva pudesse ser preenchida pela subjetividade e deste modo, o momento vivenciado pudesse ser subjetivado, e o produto final fosse percebido como resultado da jornada no sentido da experimentação.

"Eu tive um sonho bonito ao mesmo tempo triste, porque eu estava nas nuvens, era tudo azul, ao mesmo tempo não tinha água e estava quente. E eu estava me sentindo abafada. Eu quis representar isso num desenho. O meu pensamento, que eu queria água, lá estava quente e eu fiz (no desenho) aquelas chuvinhas porque que eu queria água naquele instante” $(\mathrm{H})$.

"Porque é um amor de mãe, saudade de mãe também e porque ele é o que me faz viver todos os dias aqui, é o que me faz superar tudo e andar pra frente mais um dia, mais uma noite, mais uma tarde... é por isso que eu fiz esse desenho de coração e dai escrevi que eu amo ele" (E).

Quando o sujeito concebe algo como próprio ou pertencente a sua história, e isto é reconhecido pelo outro numa relação terapêutica, há uma vivência de satisfação sentida como uma experiência criativa, e assim, "um movimento se torna gesto, um conteúdo se torna memória, transformado pela presença humana" (p.184) ${ }^{7}$

Assim, é no encontro com um outro que valida as ações do indivíduo que estas são tomadas enquanto produção singular e genuína, como experiências de criação de mundo. Isso possibilita o encontrar-se no outro e no mundo, contemplar aspectos de seu reconhecido pelo outro e a partir disso habitar um mundo compartilhado.

\section{O embotamento da criatividade}

Durante os atendimentos os participantes relatavam inquietações, preocupações e ansiedades decorrentes do tratamento e hospitalização: a administração dos quimioterápicos, a contagem de células sanguíneas, o medo da piora do quadro clínico o que prolongaria o tempo de internação, a pressa em voltar para casa.
"É dificil os internamentos porque a gente fica longe da família (...). Agora tem mais um ciclo, dai vai fica melhor, porque depois que eu terminar esse ciclo e a fase de neutropenia que está terminando, eu vou fazer no ambulatório. (...) E talvez eu passe por um transplante, mas isso o doutor ainda está vendo"(D).

Havia atendimentos nos quais à carga emocional se somava a piora do quadro clínico. Esta condição era vista pelos indivíduos como indicadores do prolongamento do internamento e como impossibilidade para a resolução de questões familiares e pessoais. Nesta situação, alguns participantes optaram por não realizar a atividade, pois a sua condição se apresentava como fator de embotamento da capacidade pessoal criativa ${ }^{1}$.

Entretanto, cabe ressaltar que para alguns participantes a condição clínica associada aos aspectos emocionais não se apresentavam como impedimento para a realização de atividade, apontando a capacidade pessoal para o viver criativo.

"Eu até pensei nem fazer a atividade hoje. Eu estava meio tristonha, meio pensativa das coisas. Mas ah... dai você veio pra gente fazer a atividade, já me animei e resolvi fazer" (D).

"Continuo com minhas atividades, me sinto realizada. Nem que esteja beeem fraquinha, mas se eu fizer só uma letra, pra mim já é uma atividade. Entendeu?... Já é uma vitória muito especial pra mim” $(\mathrm{H})$.

Observou-se que os encontros eram preenchidos pela criatividade do sujeito, pois a realidade vivenciada passava a se apresentar como possibilidade de criar, de colocar um toque pessoal na experiência. Winnicott ${ }^{11}$ (p.63) afirma que, "para controlar o que está fora, há que fazer coisas, não simplesmente pensar ou desejar". Assim, a realização de atividade acontecia, ainda que diante do momento adverso vivenciado.

O viver criativo emergia na aceitação do sofrimento implícito no reconhecimento de seus limites, no entanto, também se mostrava presente, no ato da apropriação simbólica do mundo, o acesso às formas possíveis do viver (que transpassa o existir), para um indivíduo não somente submetido a seu destino, mas também criador de sentido para a vida ${ }^{13,18}$.

\section{Crença religiosa}

Winnicott ${ }^{1,16}$ afirma, que nenhum ser humano está livre da tensão de relacionar o mundo subjetivo interno 
e o ambiente externo no qual vive, e que o alívio dessa tensão é proporcionado pelo espaço potencial, localizado entre a realidade psíquica pessoal e o mundo real, área intermediária, onde se localiza a experiência cultural, que abrange o brincar, a criatividade, a arte e o sentimento religioso.

Neste sentido, a religião, tal qual a arte, seria um modo de reivindicação socializada do descanso necessário aos seres humanos na tarefa de discriminar entre os fatos e a fantasia. De maneira que, recorrer à crença religiosa permite que a realidade objetiva seja expressa em sua concepção subjetiva e possibilite que passado, presente e futuro se articulem na busca de sentido para as vivências no mundo ${ }^{16,17}$.

"Ah, porque eu ia fazer um pica-pau mas dai não sei, fiz uma árvore cheia de frutos, porque é natureza, é bom. E uma igreja porque agora no momento eu preciso bastante. Então é bom. Por isso que eu desenhei uma igreja, que agora a gente tem que estar firme pra continuar senão a gente cai e não levanta né?!" (E).

"O começo é complicado, então a perda do cabelo, essa coisas, mas depois, você está ciente que você está ali... Se Deus deu pra você passar, e não adianta ficar chorando, se lamentando, tem que enfrentar" (D).

As crenças religiosas atravessam a busca de significado e sentido pela pessoa em estado de sofrimento ou doença, e influenciam questões como diagnóstico, restabelecimento e prognóstico ${ }^{19}$.

A presente pesquisa observou que a despeito de ter religião ou não, os participantes demonstravam uma crença religiosa que perpassava a busca de sentido para o sofrimento, a doença e o tratamento, o que parecia se apresentar como promotor de subsídios para o enfrentamento do momento vivenciado. Percebia-se que havia neste movimento um ato criativo, pois por meio da religiosidade, era possível construir significados frente à realidade experimentada, atribuindo a esta uma dimensão pessoal e singular.

\section{CONSIDERAÇÕES FINAIS}

No presente estudo, observou-se na experiência de adoecimento orgânico e na vigência de tratamento

\section{REFERÊNCIAS}

1. Winnicott DW. (1950) A criatividade e suas origens. In: Winnicott DW. O brincar e a realidade. Rio de Janeiro: Imago; 1975. acompanhada da hospitalização, que a possibilidade de produzir algo se constituiu como forma de apropriação simbólica, onde o processo de realização de uma atividade foi utilizado em prol da manifestação da subjetividade.

No ato criativo e no produto produzido se manifesta a expressão de vivencias no mundo, histórias individuais eram contadas, e neste sentido, tornavase viável que as experiências que constituam a vida do sujeito ganhassem alguns significados organizadores do caos, estranheza e conflitos. A própria experiência de estar vivo e criar coisas, se tornava o cerne de sustentação de outras experiências no cotidiano.

Contudo, também foi possível perceber que o enfrentamento da realidade repercute diretamente no modo de agir do indivíduo sobre o mundo e conduz a um prejuízo da capacidade criativa em relação à vida, parecendo apontar a condição de submissão ao contexto, conduzindo a impossibilidade de criar, levando o sujeito a inibir suas ações sobre o meio e não permitir-se envolver na realização de atividade.

Mas ao contrário desta situação, muitos foram os encontros no qual a realização de atividade aconteceu, ainda que diante da condição adversa vivida, sendo possível notar que a proposta para que algo fosse criado se apresentava como um disparador para que o impulso criativo emergisse. Estabelecia-se um convite à ação, para que se deixasse o estado de pura submissão e trilhasse um caminho rumo à superação, pela via da construção e criação.

Para a terapia ocupacional a criação de objetos é promotora de saúde, e pode se constituir enquanto instrumental terapêutico, de forma que no contexto deste estudo, tal concepção assumiu caráter fundamental, pois possibilitou ao sujeito viver o cotidiano como espaço de criatividade e de produção.

Isto foi possível através do respeito e do reconhecimento do ato criativo enquanto expressão da subjetividade de quem o realizava, considerando o modo particular que cada participante utilizava para vivenciar a experiência de criação e vislumbrando em todo o processo de realização de atividade - uma via de comunicação que revelava algo do seu criador, contava de uma especificidade sempre presente. 
de Janeiro: Imago; 1975.

3. Pinheiro N. E então doutora, eu vou ficar bem? Reflexões sobre clínica, criatividade e vida. Rev Polêmica. 2007;19:19. Disponível em: http://www.polemica.uerj.br/pol19/oficinas/ artigos/lipis_3.pdf Acesso em: 01 fev. 2012.

4. Dias EO. A teoria do amadurecimento de DW Winnicott. Rio de Janeiro: Imago; 2003.

5. Outeiral JO. Transicionalidade e criatividade: rabiscos sobre o viver criativo. J Psicanal, São Paulo. 2010;43(78):91-8. Disponível em: http://pepsic.bvsalud.org/pdf/jp/v43n78/ v43n78a07.pdf

6. Oliveira AS, Silva AA, Albuquerque I, Akashi LT. Reflexões sobre a prática de terapia ocupacional em oncologia na cidade de São Carlos. Cad Ter Ocup UFSCar. 2003;11(2):118-23. Disponível em: http://www.cadernosdeterapiaocupacional. ufscar.br/index.php/cadernos/article/view/198/153

7. Mecca RC, Castro ED. Experiência estética e construção de significados na atenção da terapia ocupacional em saúde mental. Rev Ter Ocup Univ São Paulo. 2009;20(3):1807. Disponível em: http://www.ip.usp.br/laboratorios/lapa/ versaoportugues/2c27a.pdf

8. Turato ER. Introdução à metodologia da pesquisa clínicoqualitativa - definição e principais características. Rev Portuguesa Psicossom, Porto, Portugal. 2000;29(1):93-108. Disponível em: http://www.redalyc.org/pdf/287/28720111.pdf

9. Boni VD, Quaresma SJ. Aprendendo a entrevistar: como fazer entrevistas em ciências sociais. Rev Eletrônica PósGraduandos Sociol Política UFSC. 2005;2(1):3. Disponível em: http://www.periodicos.ufsc.br/index.php/emtese/article/ view/18027/16976 Acesso em: 16 jun. 2013.

10. Bardin L. Análise de conteúdo. Lisboa: Edições 70; 1994.
11. Winnicott DW. (1958) O brincar. Uma exposição teórica. In: Winnicott DW. O brincar e a realidade. Rio de Janeiro: Imago; 1975.

12. Porto FFA, Bittencourt MIGF. O tempo para os que esperam: reflexões a partir do atendimento psicológico a pacientes na Unicor de um hospital público da cidade do Rio de Janeiro. Rev SBPH, Rio de Janeiro. 2009;12(2):43-53. Disponível em: http://pepsic.bvsalud.org/pdf/rsbph/v12n2/v12n2a05. pdf

13. Bittencourt MIGF. Reflexões sobre o tempo: instrumentos para uma viagem pelo ciclo vital. Psychê, São Paulo. 2005;9(15):93-104. Disponível em: http://pepsic.bvsalud. org/pdf/psyche/v9n15/v9n15a08.pdf

14. Winnicott DW. (1971). A atividade criativa e a busca do eu (self). In: Winnicott DW. O brincar e a realidade. Rio de Janeiro: Imago, 1975.

15. Franco SG. A criatividade na clínica psicanalítica. Pulsional Rev Psicanal. 2004;17(178):34-40. Disponível em: http:// pulsional.com.br/rev/178/4.pdf

16. Winnicott DW. (1967) A localização da experiência cultural. In: Winnicott DW. O brincar e a realidade. Rio de Janeiro: Imago; 1975.

17. Winnicott DW. A natureza humana. Rio de Janeiro: Imago; 1990.

18. Winnicott DW. O brincar e a realidade. Rio de Janeiro: Imago; 1975.

19. Genaro Junior F. Considerações sobre a constituição do self e da religiosidade na pessoa humana. Estudos Psicol, Campinas. 2008;25(4):527-33. Disponível em: http://www. scielo.br/pdf/estpsi/v25n4/a07v25n4.pdf

Recebido para publicação: 22/02/2013

Aceito para publicação: 15/06/2013 